\title{
Hydrodynamic hull form optimization using parametric models
}

\author{
Soonhung Han $\cdot$ Yeon-Seung Lee $\cdot$ Young Bok Choi
}

Received: 1 April 2011/Accepted: 28 October 2011/Published online: 1 February 2012

(C) The Author(s) 2012. This article is published with open access at Springerlink.com

\begin{abstract}
Hydrodynamic optimizations of ship hull forms have been carried out employing parametric curves generated by fairness-optimized B-Spline form parameter curves, labeled as F-Spline. Two functionalities of the parametric geometry models are used in the present study: a constrained transformation function to account for hull form variations and a geometric entity used in full parametric hull form design. The present F-Spline based optimization procedure is applied to two distinct hydrodynamic hull form optimizations: the global shape optimization of an ultra-large container ship and the forebody hull form for the hydrodynamic optimization of an LPG carrier. Improvements of ship performance achieved by the proposed F-Spline procedure are demonstrated through numerical experiments and through correlations with experimental data. The ultra-large containership was built and delivered to the ship owner. The present study validates the effectiveness of the proposed hydrodynamic optimization procedure, ushering in process automation and performance improvement in practical ship design practices.
\end{abstract}

S. Han · Y.-S. Lee $(\bowtie)$

Department of Ocean System Engineering, KAIST,

291 Daehak-ro, Yuseong-gu, Daejeon 305-701,

Republic of Korea

e-mail: yslee132@kaist.ac.kr

S. Han

e-mail: shhan@kaist.ac.kr

Y. B. Choi

Hydrodynamics R\&D Group, Ship and Ocean R\&D Institute,

Daewoo Shipbuilding and Marine Engineering Co., Ltd.

(DSME), 85, Da-dong, Jung-gu, Seoul 100-180,

Republic of Korea

e-mail: ybchoi@dsme.co.kr
Keywords Fairness optimized B-Spline form parameter curve $\cdot$ Constrained transformation function - Full parametric hull form design - Hydrodynamic optimization . Fuel economic ship design · Green ship technologies

\begin{tabular}{|c|c|}
\hline List of symbols & \\
\hline AP & Aftward perpendicular \\
\hline$A_{\mathrm{M}}$ & Midship section area \\
\hline$B$ & Maximum beam \\
\hline$C_{\mathrm{B}}=\nabla /\left(L_{\mathrm{PP}} B T\right)$ & Block coefficient \\
\hline$C_{\mathrm{F}}$ & $\begin{array}{l}\text { Frictional resistance } \\
\text { coefficient }\end{array}$ \\
\hline$C_{\mathrm{M}}=A_{\mathrm{M}} /(B T)$ & $\begin{array}{l}\text { Sectional area coefficient at } \\
\text { midships }\end{array}$ \\
\hline$C_{\mathrm{P}}=\nabla /\left(L_{\mathrm{PP}} A_{\mathrm{M}}\right)=C_{\mathrm{B}} / C_{\mathrm{M}}$ & Prismatic coefficient \\
\hline$C_{\mathrm{R}}$ & $\begin{array}{l}\text { Residual resistance } \\
\text { coefficient }\end{array}$ \\
\hline$C_{\mathrm{TS}}$ & $\begin{array}{l}\text { Total resistance coefficient in } \\
\text { full scale }\end{array}$ \\
\hline$C_{\text {FITTC }}$ & $\begin{array}{l}\text { Frictional resistance } \\
\text { coefficient by ITTC }\end{array}$ \\
\hline$C_{\mathrm{W}}$ & $\begin{array}{l}\text { Wave resistance coefficient } \\
\text { from pressure integration }\end{array}$ \\
\hline$F_{\mathrm{N}}$ & Froude number \\
\hline FP & Forward perpendicular \\
\hline$L_{\mathrm{PP}}$ & $\begin{array}{l}\text { Length between } \\
\text { perpendiculars }\end{array}$ \\
\hline$L_{\mathrm{E}}$ & Length of SAC entrance \\
\hline$L_{\mathrm{M}}$ & $\begin{array}{l}\text { Length of parallel middle } \\
\text { body }\end{array}$ \\
\hline$L_{\mathrm{R}}$ & Length of run \\
\hline$P_{\mathrm{D}}$ & Delivered power \\
\hline$R_{\mathrm{T}}$ & Total resistance \\
\hline$R_{\mathrm{TM}}$ & $\begin{array}{l}\text { Total resistance in model } \\
\text { scale }\end{array}$ \\
\hline
\end{tabular}




$\begin{array}{ll}R_{\mathrm{TS}} & \text { Total resistance in full scale } \\ R_{\mathrm{WP}} & \begin{array}{l}\text { Wave resistance from wave } \\ \text { cut analysis }\end{array} \\ R_{\mathrm{A}} & \text { Correlation allowance } \\ R_{\mathrm{AA}} & \text { Wind resistance } \\ R_{\mathrm{FITTC}} & \text { Frictional resistance by ITTC } \\ S & \text { Wetted surface area } \\ T & \text { Design draft } \\ T_{\mathrm{FP}} & \text { Design draft at forward } \\ & \text { perpendicular } \\ T_{\mathrm{AP}} & \text { Design draft at aftward } \\ & \text { perpendicular } \\ \nabla & \text { Volume of displacement }\end{array}$

$\begin{array}{ll}\text { Abbreviations } \\ \text { CAD } & \text { Computer aided design } \\ \text { CAE } & \text { Computer aided engineering } \\ \text { CFD } & \text { Computational fluid dynamics } \\ \text { DoE } & \text { Design-of-experiments } \\ \text { DWL } & \text { Design waterline } \\ \text { EFD } & \text { Experimental fluid dynamics } \\ \text { FOB } & \text { Flat of bottom } \\ \text { FOS } & \text { Flat of side } \\ \text { F-Spline } & \text { Fairness-optimized B-Spline form parameter curve } \\ \text { ITTC } & \text { International towing tank conference } \\ \text { LCB } & \text { Longitudinal center of buoyancy } \\ \text { PMB } & \text { Parallel middle body } \\ \text { RANS } & \text { Reynolds-averaged Navier-Stokes equations } \\ \text { SAC } & \text { Sectional area curve } \\ \text { SBD } & \text { Simulation based design }\end{array}$

\section{Introduction}

Green ship technologies are gaining in importance in diverse areas of ship design. Because $\mathrm{CO}_{2}$ emission levels are directly related to fossil fuel consumption, shipbuilding industries are focusing on developing new design concepts and technologies towards fuel economic ship design including the use of new propulsion devices and renewable energy sources. Hydrodynamic optimal shape designs are one component of the overall fuel economic design, although the percentage reduction of $\mathrm{CO}_{2}$ emission can be achieved 2-3\% at most. However, given the prevailing ship construction process, it is an indispensable step, because hull form design is a starting point of the new shipbuilding process and it influences resistance and propulsion performance. In addition to its hydrodynamic effects, hull form design influences costs, the construction process and safety considerations in shipyards.

There are three core technologies used for hydrodynamic hull form optimization: geometric modeling, hydrodynamic analysis, and optimization technologies.
Implementation of these technologies as tools for ship design requires a sufficient understanding of each technique, the use of practical design experience and methodologies in the optimization process, and the appropriate evaluations of the optimization results to verify improved ship operation performance. With the development of each technology, CFD simulation-based ship design (SBD) has continuously improved and become more appropriate for practical use [3-9, 16, 17, 26, 27, 30-32, 34]. The current CFD simulations make it possible to reliably predict and validate ship resistance, propulsion performance and seakeeping performance $[4,13,29,35]$. Although ship design is generally a multi-objective optimization problem, objective function evaluations based on a RANS solver require effectiveness and efficiency. Effective global optimization algorithms such as variable fidelity models, filled function-based algorithms, and a particle swarm optimization have been introduced for SBD [3, 21, 24, 32].

In the field of ship geometry design, increasingly sophisticated design methodologies are continuously suggested and validated [6, 9, 15-20, 22, 23, 26, 28, 32]. An SBD project entitled 'FANTASTIC', whose goal was to improve the functional design of ship hull shapes, was implemented over a period of 3 years by 14 European partners [16]. As a result, three approaches to shape modeling emerged: ship parametric modeling using Friendship-modeler software, a template approach involving the use of NAPA [16], and shape transformation functions via GMS/Facet [16]. Major progress in the optimization process has been obtained through the use of parametric modeling, which provides the most flexible ship design variations. Finally, geometric modeling for SBD addresses the problem of shape generation and transformation as necessary to generate design variations with the required flexibility and functionality. These efforts not only optimize ship hull performance but also ensure the effectiveness of the automated design process.

The simplest and, therefore, most widely used method of generating hull shape parameters is the fitting of discrete ship offset data with parametric representations such as polynomials, cubics, and Bezier and B-Spline curves or surfaces. The discrete data obtained, including hull offset data and control points, are directly used as design variables to modify the shape. This approach provides flexibility in controlling each control point but results in less functionality because the high degree of freedom in control points variations can cause deviations from the desired shape $[10,26,33]$.

In a more sophisticated method, the ship shape is partitioned into several sections, defined within several boxes and controlled by using a small number of control points as design variables. An effective grouping of control points can yield sufficiently large and realistic changes in the hull 
form [14, 16, 31]. If the hull shape is generated using form parametric data and a fairing process, the shape can be generated using a highly sophisticated fully parametric model. This fully parametric model generates the entire hull surface from a limited parameter set based on higherlevel geometrical properties [1, 6, 18-20, 28].

A set of transformation functions can be defined by types of data including analytical curves, surface data, and discrete data. They can then be used in any type of geometry, offset data, or functional model. Although the formulation of the transformation function is a critical issue in geometric variation, it is mainly dependent on geometric modeling and the optimization problem $[2,12$, 26, 27].

From a practical viewpoint, the geometric modeling process for ships is expected to be simple and similar to the design approaches with which ship designers are already familiar. The principal methods of ship design include the distortion transformation of a given hull form and the $\mathrm{ab}$ initio design of a new hull form using form parameters. In the present study, distortion transformation and form parameter design based on the F-Spline technique were investigated [6, 7]. Two hull form optimization approaches were used with practical ship designs. The applicability and subsequent improvements in hydrodynamic performance of these techniques are discussed in this article.

The commercial software SHIPFLOW [13] was used as a CFD solver, and FS-Framework [1, 2, 6-9] was used as a geometric modeler and optimizer. The resistance and propulsion performance tests were performed at the Hamburg ship Model Basin (HSVA, Germany) and Maritime and Ocean Engineering Research Institute (MOERI, Korea), respectively.

\section{Parametric hull form design}

The process of curve generation begins with the complete mathematical definition of the curve from a set of given data elements of the curve. Since the data elements usually describe only a subset of the properties of the curve shape, the results of the curve generation process may vary. These results depend on the choice of mathematical curve representations and the properties of the generation process [18-20]. In this study, fairness-optimized parametric curves with constraints were used. These curves were represented by B-Spline curves and generated using the fairness optimization process with sets of form parameters as constraints. These fairness-optimized parametric curves have been used as unconstrained transformation functions for distortion transformation and as geometric entities to generate new hull form for the form parameter design.
2.1 Fairness-optimized parametric curve with constraints $[2,6,19,20]$

The general formulation of the fairness-optimized parametric curve with constraints follows below:

Let $\boldsymbol{r}(\mathrm{t})$ be a vector valued free form curve parameterized by $t$

$\boldsymbol{r}(t)=(x(t), y(t), z(t))$

Minimizing the $m$ th order fairness criterion yields $L_{m}$, which is given by

$L_{m}=\int_{0}^{1}\left(D^{m} \boldsymbol{r}(t)\right)^{2}$, where $D^{m}=d^{m} / \mathrm{d} t^{m}$

and is subject to the following constraints:

- Distance constraints: The Euclidean distance between the given data points $P_{i}$ and the resulting $\boldsymbol{r}(t)$, taken at the associated parameter knot $t_{i}$, weighted by $w_{i}$, and squared, must be no greater than the error tolerance $\varepsilon$. In normalized form for $n+1$ data points,

$A=\sum_{i=0}^{n}\left\{w_{i}\left(\boldsymbol{r}\left(t_{i}\right)-P_{i}\right)\right\}^{2}-\varepsilon \leq 0, \varepsilon \geq 0$

- End constraints: For the first and last points on the curve, tangent vectors $\boldsymbol{Q}_{i}$ and curvature vectors $\boldsymbol{K}_{i}$, $i=0$, or $n$, may be given as follows:

Type I end conditions:

$$
E_{1}=D^{1} \boldsymbol{r}\left(t_{i}\right)-\boldsymbol{Q}_{i}=0
$$

Type II end conditions:

$$
E_{2}=D^{2} \boldsymbol{r}\left(t_{i}\right)-\boldsymbol{K}_{i}=0
$$

- Area constraints: The actual area under a curve, $S$, shall match a given area value, $S_{0}$ :

$F=S-S_{0}=0$

- Other constraints: Many other types of constraints can be imposed in equality or inequality form.

This constrained optimization problem is formulated to minimize the unconstrained objective functional $I$ :

$\min I=L_{m}+\lambda A^{\prime}+\mu_{1} E_{1}+\mu_{2} E_{2}+v F, \quad A^{\prime}=A+d^{2}$

where $\lambda, \mu_{i}$, and $v$ are the Lagrange multipliers and $d^{2}$ is a slack variable. If this is an interpolation problem, $d^{2}$ equals zero. The degree of the fairness criterion affects the characteristics of the shape. Table 1 shows the form parameters of a planar curve. Figure 1 presents an example of an 
Table 1 Form parameters describing a planar curve

\begin{tabular}{|c|c|c|c|c|c|c|}
\hline & \multicolumn{2}{|l|}{$\mathrm{C} 1$} & \multicolumn{2}{|c|}{ C2 (circle) } & \multicolumn{2}{|l|}{$\mathrm{C} 3$} \\
\hline & $i=0$ & $i=1$ & $i=0$ & $i=1$ & $i=0$ & $i=1$ \\
\hline Position $X_{i}, Y_{i}(\mathrm{~m})$ & 1,0 & 0,1 & 1,0 & 0,1 & 1,0 & 0,1 \\
\hline Tangent angle $Q_{i}\left({ }^{\circ}\right)$ & 90 & 180 & 90 & 180 & 90 & 180 \\
\hline Curvature $K_{i}$ & 4.80 & 4.80 & 1 & 1 & -0.624 & -0.624 \\
\hline Area $S\left(\mathrm{~m}^{2}\right)$ & \multicolumn{2}{|c|}{$\pi / 4 / 1.25$} & \multicolumn{2}{|l|}{$\pi / 4$} & \multicolumn{2}{|c|}{$1.25 \times \pi / 4$} \\
\hline Centroid $X_{\mathrm{C}}, Y_{\mathrm{C}}(\mathrm{m})$ & \multicolumn{2}{|c|}{$0.37,0.37$} & \multicolumn{2}{|c|}{$0.42,0.42$} & \multicolumn{2}{|c|}{$0.49,0.49$} \\
\hline Fairness $E_{2}$ & \multicolumn{2}{|l|}{8.72} & \multicolumn{2}{|l|}{6.09} & \multicolumn{2}{|l|}{15.14} \\
\hline
\end{tabular}

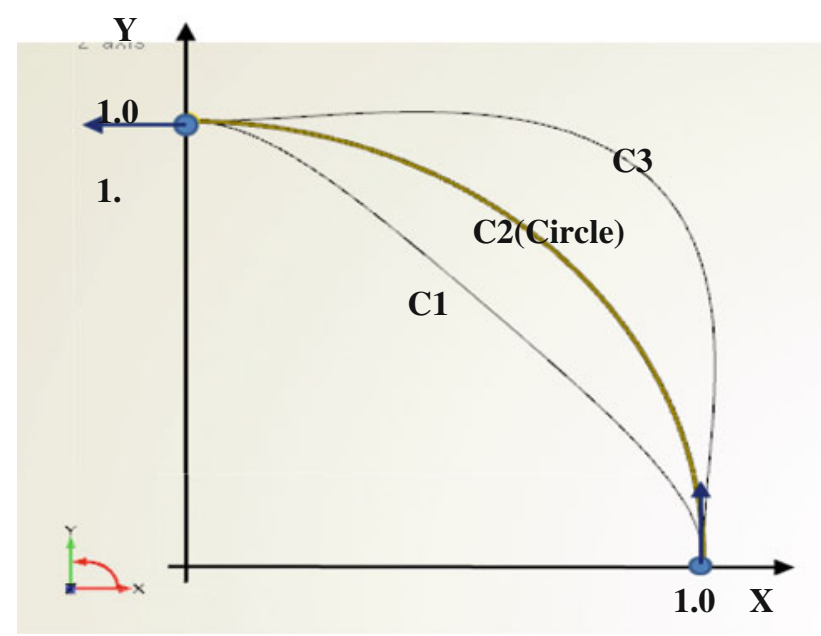

Fig. 1 Fairness-optimized parametric curve with different area constraints

F-Spline with three different area constraints. The positions and tangent angles are given as input form parameters. They are the same as those of $\mathrm{C} 2$, the unit circle. The curve is generated from the point on the $x$-axis in a counterclockwise direction. The properties of the generated F-Spline are compared by means of the curvature, the centroid and their fairness.

\subsection{Distortion transformation based on fairness- optimized B-Spline form parameter curves (F-Spline) with constraints}

Distortion is the transformation of a given hull form via transformation functions to obtain new hull form data. A transformation function is a mathematical formulation that defines the degree of transformation of a given geometry necessary to achieve a certain new shape. In ship design, it is conventionally used to transform basic ship curves. The flexibility and variability of the distortion transformation depend on the geometrical properties and applicability of the transformation function. There are two types of transformation functions: unconstrained and constrained.
The unconstrained transformation function is a mathematical formulation used to define the degree of transformation of the given geometry without constraints. It can be defined in any type of function and applied to any part of the geometry for a complex and flexible transformation. This function is mostly used in hydrodynamic hull form optimization because it is easy to implement. However, an additional iteration is required to ensure that the design requirements are met and the target geometry is achieved. This function is, therefore, typically used for small local variations [16, 26, 27, 30].

The constrained transformation function is a mathematical formulation used to define the degree of transformation of the given geometry with design constraints. This function should be derived so as to satisfy design requirements before it is applied to hull form variation. The essential prerequisite to define the mathematical relationship between the degree of local transformation and the design requirements makes the application complicated. Therefore, the functions employed so far generally feature a simple form and fewer degrees of freedom [6, 12].

The Lackenby transformation [12] is a classical distortion based on a constrained transformation function expressed by a first or second degree polynomial. These polynomial-based transformation functions are analytically formulated and applied to SAC variation to derive a new required SAC. Because it yields robust and effective hull form distortions, this process is often used in the preliminary ship design phase. However, the Lackenby transformation has limited flexibility because of its simple polynomial-based transformation function. The function is expressed by a few form parameters, such as $C_{\mathrm{P}}, \mathrm{LCB}, L_{\mathrm{R}}$ and $L_{\mathrm{E}}$.

In the present study, F-Spline was used as a constrained transformation function for the SAC distortion transformation [1, 2, 6-9]. Two F-Splines were used to define the transformation functions for the run and entrance parts of $\mathrm{SAC}$, respectively. The form parameters describing the F-Spline include the degree of changes in the position, angle, and volume as well as centroid (LCB), as shown in Fig. 2. In this case, the curvature need not be considered. 
Fig. 2 SAC distortion based on F-Spline transformation function

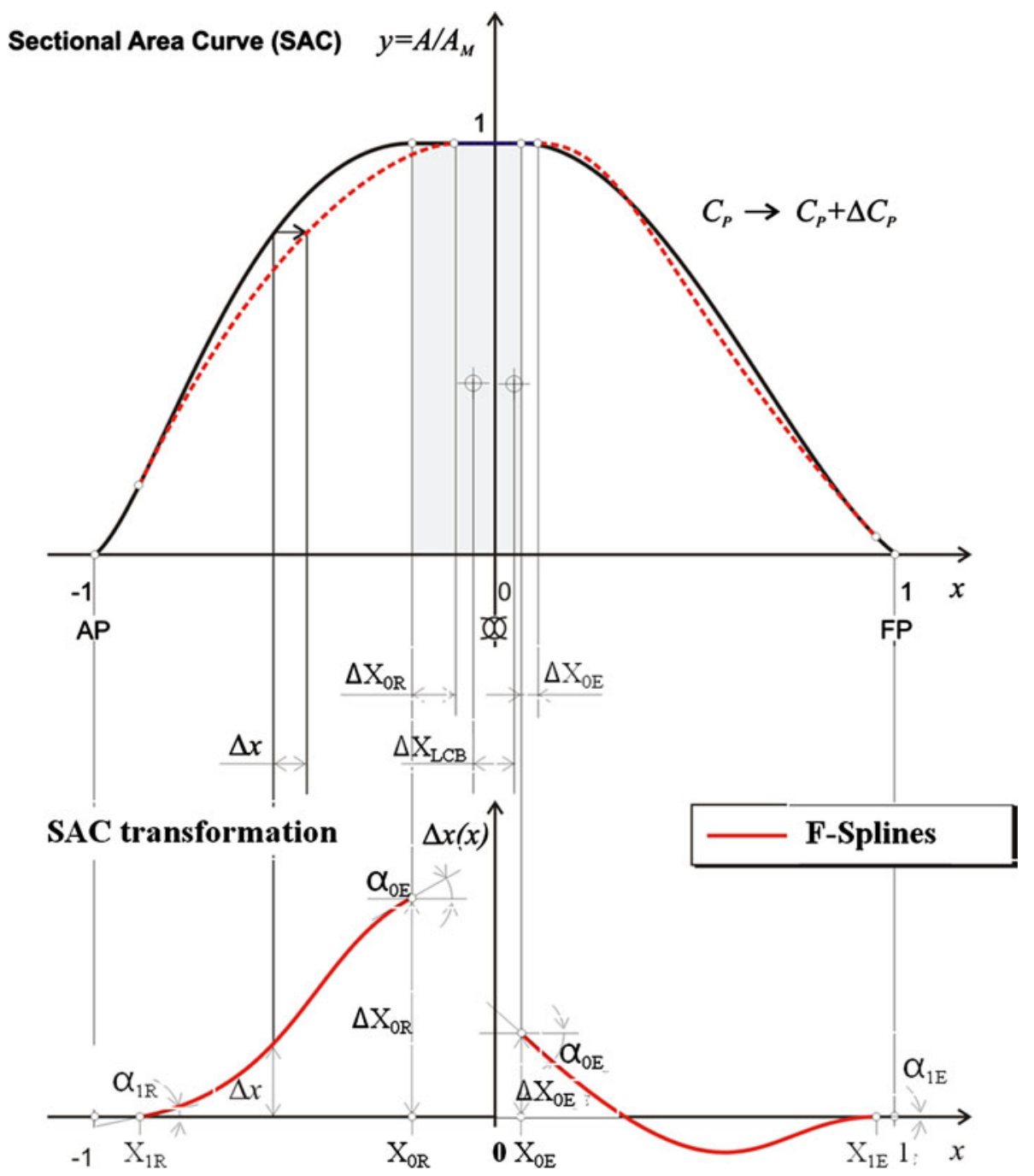

The B-Spline curves that satisfy the required form parameter constraints can be optimized for the second degree fairness criterion. The generation process for the transformation function for the SAC is as follows [2]:

- Define an open uniform third degree B-Spline curve with $n+1$ vertex points.

$\boldsymbol{r}(t)=\left(\begin{array}{l}x(t) \\ y(t)\end{array}\right)=\sum_{i=0}^{n} \boldsymbol{B}_{i} \cdot N_{i k}(t)$

- Minimize the second order fairness criterion:

$E_{2}=\int_{t_{B}}^{t_{E}}\left\{\left(\frac{d^{2} x}{\mathrm{~d} t^{2}}\right)^{2}+\left(\frac{d^{2} y}{\mathrm{~d} t^{2}}\right)^{2}\right\} \mathrm{d} t$

which is subject to m-equality constraints:

$h_{i}=\mathrm{FP}_{\text {initial }}-\mathrm{FP}_{\text {irequired }}=0, \quad i=1, \ldots, m$

where $\mathrm{FP}_{i}$ represents the form parameter constraints listed in Table 2 and $m$ is the number of constraints to be considered. This constrained optimization problem can be reformulated as an unconstrained problem using the Lagrange multiplier method.

$F=E_{2}+\sum_{i=1, m} \lambda_{i} h_{i}=0$

The problem is formulated to minimize the function $F$ and the unknowns are form parameters and Lagrange multipliers. Thus, the minimum conditions are

$\frac{\partial F}{\partial \mathrm{FP}_{i}}=0, \frac{\partial F}{\partial \lambda_{i}}=0, \quad i=1, \ldots, m$

This yields a nonlinear system of equations for the unknown, vertex points and Lagrange multipliers that can be solved numerically.

The ability to control the angle parameter of each part of the SAC using the proposed approach (10) is the critical functionality that distinguishes it from the Lackenby transformation. The differential form parameters expressed as $\Delta \alpha$ in Table 2 have a significant influence on resistance 
Table 2 Form parameter constraints for SAC transformation function

\begin{tabular}{|c|c|c|c|c|}
\hline & \multicolumn{4}{|c|}{ Form parameter constraints $\mathrm{FP}_{i}$} \\
\hline & \multicolumn{2}{|l|}{ Run part } & \multicolumn{2}{|c|}{ Entrance part } \\
\hline & Beginning $t_{\mathrm{B}}=X_{0 \mathrm{R}}$ & $\begin{array}{l}\text { End } \\
t_{\mathrm{E}}=X_{1 \mathrm{R}}\end{array}$ & $\begin{array}{l}\text { Beginning } \\
t_{\mathrm{B}}=X_{0 \mathrm{E}}\end{array}$ & $\begin{array}{l}\text { End } \\
t_{\mathrm{E}}=X_{1 \mathrm{E}}\end{array}$ \\
\hline Position & $\Delta X_{\mathrm{OR}}$ & $\Delta X_{1 \mathrm{R}}$ & $\Delta X_{0 \mathrm{E}}$ & $\Delta X_{1 \mathrm{E}}$ \\
\hline Tangent angle & $\Delta \alpha_{0 R}$ & $\Delta \alpha_{1 \mathrm{R}}$ & $\Delta \alpha_{0 \mathrm{E}}$ & $\Delta \alpha_{1 \mathrm{E}}$ \\
\hline Area & $\Delta C_{\mathrm{P}}$ & & & \\
\hline Centroid of area & $\Delta X_{\mathrm{LCB}}$ & & & \\
\hline
\end{tabular}

performance, transforming the entrance angle and stern profile shape. Figure 2 shows an example of a SAC distortion based on F-Spline transformation function

\subsection{Form parameter design based on F-Spline with constraints}

An arbitrary ship hull form can be fully parametrically expressed by suitably combining the form parameters constituting the basic curves and hull section frames. When the parametric design of the longitudinal basic curves is generated using fairness-optimized parametric curves, transversal basic curves can be generated. Similarly, if the transversal sections are derived by parametric modeling, a set of surfaces that interpolate or closely approximate the design sections is generated. Thus, efficient and effective form variations based on the parametrically generated hull form surfaces are possible [6, 18-20]. However, since there are many form parameters that make up each form parameter basic curve, and since there are possible correlations among the form parameters, it is not straightforward to determine the parametric input data sets. The increasing flexibility of the basic curve designs makes the design process increasingly complex.

Basic curves can be parameterized using the F-Splines. Since the curves are geometrically optimized for fairness to meet the least number of curve requirements, the use of F-Spline reduces the complexity arising from the parameter input sets, while increasing flexibility and improved shape quality $[1,2,6,7]$.

In this study, the forebody hull form of an LPGC was fully parameterized for the shape variation, whereas the aftbody hull form was kept unchanged during the optimization. The parametric model of the forebody hull form includes global parameters such as ship dimensions and basic curves indicating the longitudinal distribution of the geometric parameters such as position, tangent, curvature, and area. Table 3 shows basic curves to define the essential main shape characteristics of the ship. Figure 3 shows the fully parametric forebody model based on several basic curves and the form parameters defining those basic curves [9].
Table 3 Basic curves describing a hull form

\begin{tabular}{lll}
\hline & Curve & Symbol \\
\hline Position & Design waterline & DWL \\
& Flat of side curve & FOS \\
& Center plane curve & CPC \\
& Flat of bottom curve & FOB \\
& Deck & DEC \\
Tangent angle & Tangent angle at beginning and end & TAB, TAE \\
Curvature & Curvature at beginning and end & CAB, CAE \\
Area & Sectional area curve & SAC \\
Centroid of area & Vertical moments of sectional area & VMS \\
& Lateral moments of sectional area & LMS \\
\hline
\end{tabular}

The parametric modeling was based on the given shape by importing the IGES file. Based on the IGES surface, a dense offset distribution for the forebody and aftbody was generated as offset data. The form parameter value describing each basic curve of the initial hull form was extracted from the given initial hull form to begin the parametric modeling. The number of form parameters is strongly dependent on the shape variation strategy. To fully exploit the F-Spline optimization and develop a completely new type of forebody hull form, approximately 80 form parameters were used for the parametric modeling. The relationships among the parameters were investigated in depth and sharing points were identified. A well-developed structure of parameter dependencies can help to avoid unnecessary increases in parameter inputs and degeneration in hull form variation.

\section{SAC optimization of an ultra-large containership based on a constrained F-Spline transformation function}

The size of containerships has been continuously increasing. With the expansion plan for the new Panamax, the largest size of operating containerships will reach around 14,000 TEU. Containerships of approximately 18,000 TEU are also currently under development. The block coefficient 


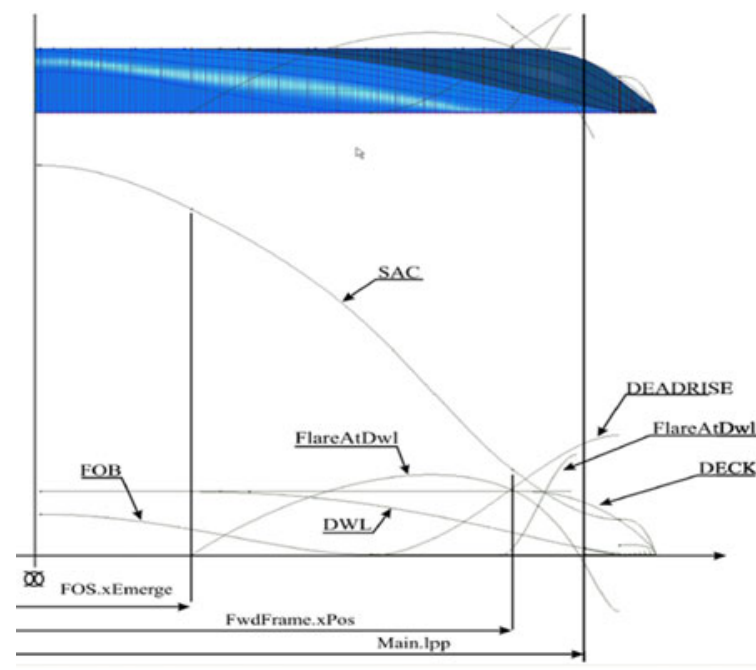

\begin{tabular}{|c|c|c|c|}
\hline \multicolumn{4}{|l|}{ Free Variables } \\
\hline MainparallelOffset & active & 17.9956 & [9.75:29.25] \\
\hline FOSxEmerge & active & 1.24468 & [1.2:1.25] \\
\hline FOBtanForEnd & active & $\cdot 9.35547$ & {$[-20: 0]$} \\
\hline FOBareaCoefffor & active & 0.514307 & [0.5:0.55] \\
\hline BBowlength & inactive & 6 & {$[5: 6]$} \\
\hline BBowBeamAtFp & active & 5.82617 & {$[4: 6]$} \\
\hline BBowBeamElevAtfp & active & 7.16211 & [6:8] \\
\hline DwlT anAtFp & active & $\cdot 12.4941$ & {$[-20: 6]$} \\
\hline DwilTanAtfos & active & -0.936523 & $3[-1: 0]$ \\
\hline DwlAreaCoefffor & active & 0.610811 & [0.6:0.63] \\
\hline FwdFrameAreaCoeff & active & 0.845996 & {$[0.8 .0 .9]$} \\
\hline SACareaCoeffiAfFosEmerge & active & 0.84251 & {$[0.82: 0.87]$} \\
\hline SAClanAtF wdFrame & active & $\cdot 61.6943$ & {$[-70: 55]$} \\
\hline SAClanAlfp & active & .32 .0605 & {$[-70: 20]$} \\
\hline SACmzAlf osEmerge & active & $\cdot 11.0059$ & [-15:-5] \\
\hline - FlareAtD wlatFwdFrame & active & 4.32129 & [0:15] \\
\hline - DEADRISE atF wdFrame & active & 15.0195 & [0:20] \\
\hline -BBowZTopFp & inactive & 0.675 & {$[-0.7: 0.6]$} \\
\hline -BBowxBase & inactive & 190 & [190:191] \\
\hline
\end{tabular}

Fig. 3 Fully parametric forebody model and form parameters defining the basic curves

$C_{\mathrm{B}}$ reaches 0.7 , and the design speed range decreases to approximately 0.2 in $F_{\mathrm{N}}$ or even lower. The design concept for ultra-large containerships tends to make them larger, fuller and slower. They can facilitate improvements in ship fuel economy and help to create "greener" ships.

Another design trend to improve the fuel economy is the multi-objective shape optimization based on the life cycle operating conditions. The speed performance in the ballast draft condition has become increasingly important. However, it has still been a standard process for containership design in ship yards that the hull form design is conducted only for the performance in the design draft condition, and then the speed performances are generally simulated and tested at two drafts, design and ballast conditions. This section describes a procedure used to optimize the hydrodynamic hull form for an ultra-large containership. Optimal hull form has been developed only for the performance in the design draft condition.

A SAC provides an effective and simple description of global geometric properties. At the same time, it is closely related to the resistance and propulsion performance of a ship. From this point of view, the ship hull form distortion approach based on SAC transformation is one of the most effective global design methods for the preliminary design stage. The optimization procedure was performed using the SAC transformation with F-Spline as the transformation function. First, a sensitivity analysis was performed to determine the effect of each form parameter of F-Spline on the geometric properties of SAC transformations and hence on ship variations and wave resistance performance. For example, the SAC angle parameters influence the entrance angle and incident angle of the design waterline, the fullness around the parallel middle body and the transom. These shapes have a considerable influence on wave resistance performance. Second, a SAC optimization problem was formulated based on the second baseline SAC design, and the feasible form parameter range was determined using the sensitivity analysis. A formal optimization was carried out using a search method. The performance of the optimal ship was tested and the results discussed. This analysis had two main objectives:

(a) To verify whether the design variations yielded by the F-Spline transformation functions were geometrically flexible and functional and could be conveniently integrated into the classical design practice.

(b) To verify whether the design variations yielded by the F-Spline transformation functions were acceptable in terms of resistance performance.

\subsection{Design configurations}

The design configurations of the object ship are shown in Table 4. A baseline design that satisfies the main requirements was developed. It had a relative V-type forebody hull and a U-type aftbody hull.

\subsection{CFD simulation}

The wave profiles and wave making resistance associated with alternative ship hull designs were simulated using SHIPFLOW XPAN by FLOWTECH. SHIPFLOW provides a non-linear potential flow code that uses Rankine panels to discretize the hull and free surface. The nonlinear boundary condition was iteratively solved. Trim and sink were allowed during the simulation.

The number of panels on the hull and free surface depends on the fullness and complexity of the hull 
Table 4 Principal particulars of an ultra-large containership

\begin{tabular}{lc}
\hline & $\begin{array}{c}\text { Design } \\
\text { condition }\end{array}$ \\
\hline$F_{\mathrm{N}}$ & 0.20 \\
$C_{\mathrm{B}}$ & 0.70 \\
$L_{\mathrm{PP}}(\mathrm{m})$ & 360.0 \\
$B(\mathrm{~m})$ & 51.0 \\
$T(\mathrm{~m})$ & 14.0 \\
\hline
\end{tabular}

geometry and ship speeds mainly. A detailed verification process including grid sensitivity analysis and error estimation for the numerical predictions were undertaken for a wide range of ship series and ship speeds using SHIPFLOW. In this thesis, sensitivity analyses for panel convergence, computational range convergence and iterative convergence were performed [15]. The numerical errors that propagated in the wave resistance coefficient were estimated. The panel convergence analysis determined hull panel variation in terms of size, aspect ratio and distribution as well as free surface panel variation in terms of size per wavelength, computation region on the free surface, aspect ratio, panel distribution near the hull. The results indicated that there exist systematic error trends between simulations and experiment as a function of ship geometry and ship speeds. Using a potential code based on the SHIPFLOW analysis, a simulation-based design can be created using a comparison of the performance of alternative ship designs of the numerical configuration is carefully determined. The degree of numerical error based on the potential code is somewhat small and randomly distributed in comparison with the effect of geometric ship variation.

The hull surface was discretized using around 2,000 panels. On the longitudinal plane, a resolution of 25 panels per fundamental wavelength was utilized. The computation region of the free surface extended from $x / L=-0.5$ to 2.0 upwards and downwards, respectively, and from $y / L=0.0$ to 0.7 from side to side. To reduce oscillation, the aspect ratio of free surface panel was maintained at levels larger than 1.5 .

\subsection{Sensitivity analysis of F-Spline form parameters}

A systematic investigation of the SAC transformation was performed with respect to the form parameters for the F-Spline transformation functions for the wave resistance performance. Wave resistance is not representative of overall ship performance. However, because the sensitivity analysis including further formal optimization was based on the generalized Lackenby method, the shape topology and characteristics of the ship were not significantly changed during the process. Thus, it was possible to compare wave resistance levels only during the optimization process. However, the wetted surface area is generally monitored during the entire simulation-based optimization process.

\subsubsection{The effect of the parallel middle body (PMB) on the wave resistance}

The effect of PMB length and position on wave resistance performance was investigated during this study. The length of the $\mathrm{PMB}$, i.e., $L_{\mathrm{M}}$, in the baseline design is defined as the distance between the starting position for PMB, i.e., $X_{0 \mathrm{R}}$ and the end position for PMB, i.e., $X_{0 \mathrm{E}}$. $L_{\mathrm{M}}$ is expressed as a percentage of $L_{\mathrm{PP}}$, whereas $X_{0 \mathrm{R}}$ and $X_{0 \mathrm{E}}$ are expressed as the station number. The parameters $L_{\mathrm{M}}, X_{0 \mathrm{R}}$ and $X_{0 \mathrm{E}}$ were systematically varied by $\Delta X_{0 \mathrm{R}}$ and $\Delta X_{0 \mathrm{E}}$. They were applied to each position $X_{0 \mathrm{R}}$ and $X_{0 \mathrm{E}}$ in the baseline design and varied by intervals of $2.5 \% L_{\mathrm{PP}}(0.5$ station; see Fig. 10) respectively. The variation is shown in Table 5: Case 1 represents the baseline design. $L_{\mathrm{M}}$ is varied from $7.5 \% L_{\mathrm{PP}}$ to $15.0 \% L_{\mathrm{PP}}$ by intervals of $2.5 \% L_{\mathrm{PP}}$. An increase in $L_{\mathrm{M}}$ leads to a sharper entrance angle and a thinner stern volume because of the constant volume constraint. Figure 4 shows the SAC transformations as a function of $L_{\mathrm{M}}$ from Case 1 to Case 4 .

Figure 5 shows the percentage reduction in $C_{\mathrm{W}}$ in relation to that of the baseline design. The $C_{\mathrm{W}}$ decreases as $L_{\mathrm{M}}$ increases. The $C_{\mathrm{W}}$ reduction rate reaches a maximum of $8 \%$ with a $15 \% L_{\mathrm{PP}}$ increase in $L_{\mathrm{M}}$. $L_{\mathrm{M}}$ has a greater influence on the decrease in $C_{\mathrm{W}}$ than the variation in $X_{0 R}$. Case 4 , in which the PMB is positioned extremely in the forebody direction, exhibits a diminishing rate of decrease in $C_{\mathrm{W}}$ even with the increases in $L_{\mathrm{M}}$. Case 11 is positioned extremely in the aftbody direction. Considering that resistance performance is based on potential flow, we limit $X_{0 \mathrm{E}}$ from Station 8.0 and extend $X_{0 \mathrm{R}}$ to Station 11.0. Case 9, with an $L_{\mathrm{M}}$ of $12.5 \% L_{\mathrm{PP}}$ from Station 8.0 to Station 10.5, exhibits the most favorable resistance performance.

\subsubsection{The effect of the differential form parameters on wave resistance}

A systematic investigation of the differential form parameters $\Delta \alpha_{0 \mathrm{E}}$ and $\Delta \alpha_{1 \mathrm{E}}$ for the entrance part and $\Delta \alpha_{0 \mathrm{R}}, \Delta \alpha_{1 \mathrm{R}}$ for the run part of SAC was carried out. Four differential form parameters were systematically varied based on six cases using intervals of $15^{\circ}(\Delta)$. Therefore, the hull form variations based on the SAC transformation and wave resistance calculations were determined for all 24 cases. The positive change in the angle is expressed as $\Delta, 2 \Delta, 3 \Delta$ at AP and FP, $\Delta \alpha_{1 \mathrm{R}}$ and $\Delta \alpha_{1 \mathrm{E}}$ make the SAC sharper at each curve end and for a parallel middle angle, $\Delta \alpha_{0 R}$ and 
$\Delta \alpha_{0 \mathrm{E}}$ increase the fullness near the area. The design waterline shapes as a function of the entrance angle $\Delta \alpha_{1 \mathrm{E}}$ are shown in Fig. 6.

As shown in Fig. 7, there is a linear functional relationship between the differential parameters of the SAC and the wave resistance performance. The wave resistance performance improved with increased angle variation. The effect of the entrance angle $\Delta \alpha_{1 \mathrm{E}}$ on wave resistance performance is noteworthy. An improvement of approximately $15 \%$ in wave resistance performance was found for that angle as compared with the baseline design. The fullness of the PMB based on the changes of $\Delta \alpha_{0 R}$ and $\Delta \alpha_{0 \mathrm{E}}$ is related to wave resistance performance. The degree of steepness of the SAC was quantitatively determined based on the combination of the differential form parameters. We selected the first design variation based on the main parameter sensitivity analysis by adding the best PMB configuration and the differential form parameter configuration. The ship design was derived by independently applying Case 9 for PMB variation and the $2 \Delta$ degree of change in the entrance angle variation, $\Delta \alpha_{1 \mathrm{E}}(2 \Delta)$ to the baseline design. The degree of improvement of the first design variation in the wave pattern is evaluated with respect to the baseline design in Fig. 8.

Through the sensitivity analysis, the hull form with the fuller shape around the middle body and the sharper shape around FP and AP, namely the hat-shaped SAC, was found to be preferable. Although this trend complies with the slowly operating full ship design concept, this optimal SAC shape is valid for the ultra-large containership with the present design conditions listed in Tables 4 and 6.

Table 5 Variation cases for PMB

\begin{tabular}{|c|c|c|c|c|c|c|}
\hline \multirow[b]{2}{*}{ Case } & \multicolumn{2}{|c|}{ Parameters } & \multicolumn{3}{|l|}{ PMB } & \multirow{2}{*}{$\begin{array}{l}\Delta C_{\mathrm{W}} \\
(\%)\end{array}$} \\
\hline & $\Delta X_{0 \mathrm{R}}$ & $\Delta X_{0 \mathrm{E}}$ & $\begin{array}{l}\text { Start } \\
X_{0 \mathrm{R}}- \\
\Delta X_{0 \mathrm{R}} \\
\text { (station) }\end{array}$ & $\begin{array}{l}\text { End } \\
X_{0 \mathrm{E}}+\Delta X_{0 \mathrm{E}} \\
\text { (station) }\end{array}$ & $\begin{array}{l}\text { Length } \\
L_{\mathrm{M}}(\% \\
\left.L_{\mathrm{PP}}\right)\end{array}$ & \\
\hline 1 & $\mathbf{0}$ & $\mathbf{0}$ & 9.0 & 10.0 & 5.0 & \\
\hline 2 & & 0.5 & & 10.5 & 7.5 & -2.8 \\
\hline 3 & & 1.0 & & 11.0 & 10.0 & -4.1 \\
\hline 4 & & 1.5 & & 11.5 & 12.5 & -4.5 \\
\hline 5 & 0.5 & 0 & 8.5 & 10.0 & 7.5 & -2.6 \\
\hline 6 & & 0.5 & & 10.5 & 10.0 & -5.3 \\
\hline 7 & & 1.0 & & 11.0 & 12.5 & -6.5 \\
\hline 8 & 1.0 & 0 & 8.0 & 10.0 & 10.0 & -5.2 \\
\hline 9 & & 0.5 & & 10.5 & 12.5 & -6.8 \\
\hline 10 & & 1.0 & & 11.0 & 15.0 & -8.2 \\
\hline 11 & 1.5 & 0 & 7.5 & 10.0 & 12.5 & -6.2 \\
\hline
\end{tabular}

\subsection{SAC optimization}

The geometrical properties of SAC variation using F-Spline form parameters and the design trends for minimum wave resistance were investigated in this study. In the next step, based on the previous sensitivity analysis, the SAC optimization problem was formulated by setting a feasible range of form parameters as constraints. The first design variation was used as the second baseline design for the formulated SAC optimization process. This problem was solved using the tangent search method as an optimization technique.

Objective function: Minimize $C_{w}$

Design variables: $\Delta X_{\mathrm{C}}, \Delta X_{0 \mathrm{E}}, \Delta \alpha_{0 \mathrm{E}}, \Delta \alpha_{1 \mathrm{E}}, \Delta X_{0 \mathrm{R}}, \Delta \alpha_{0 \mathrm{R}}$

Constraints:

$$
\begin{aligned}
& -1 \leq \Delta X_{\mathrm{C}}\left(\% L_{\mathrm{PP}}\right) \leq 1 \\
& -6.175 \leq \Delta X_{0 \mathrm{E}}(m) \leq 6.175 \\
& -6.175 \leq \Delta X_{0 \mathrm{R}}(m) \leq 6.175 \\
& -20 \leq \Delta \alpha_{0 \mathrm{E}}(\text { degree }) \leq 30 \\
& -10 \leq \Delta \alpha_{1 \mathrm{E}}(\text { degree }) \leq 10 \\
& -10 \leq \Delta \alpha_{0 \mathrm{R}}(\text { degree }) \leq 10
\end{aligned}
$$

An optimal design was achieved after 37 iterations within the given convergence criterion. The wave resistance

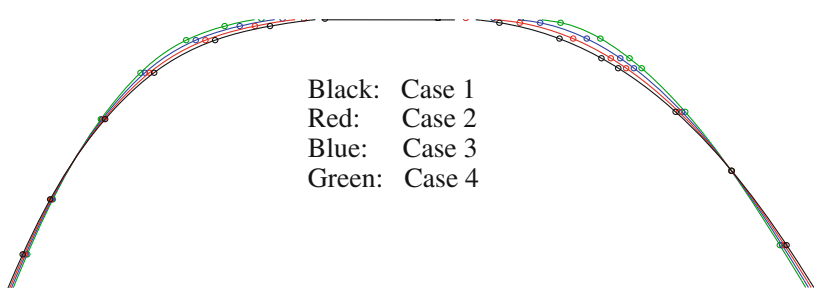

Fig. 4 SAC variations as a function of $L_{\mathrm{M}}$

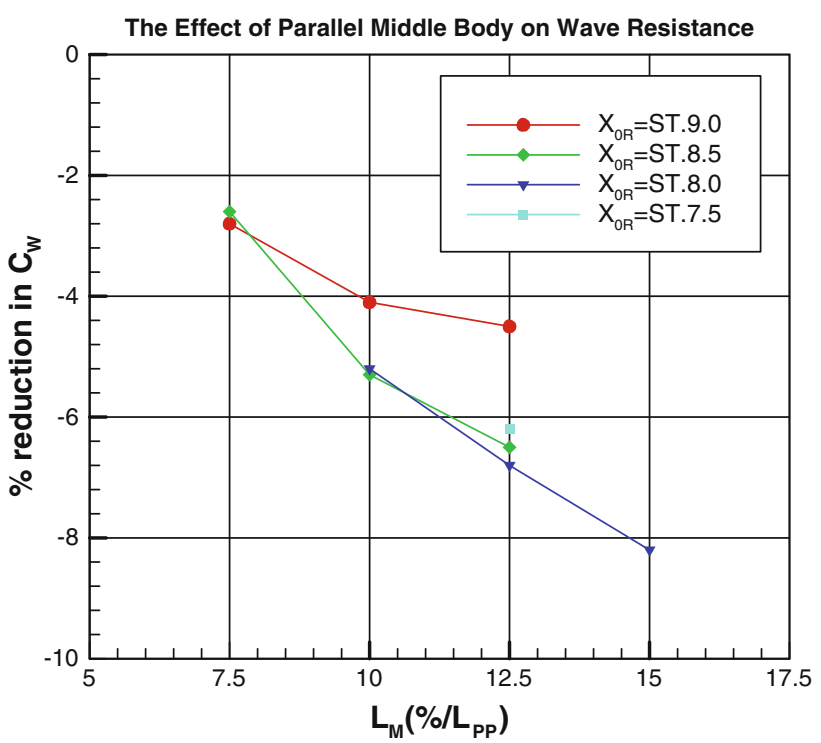

Fig. 5 Percent reduction rate of the $C_{\mathrm{W}}$ 


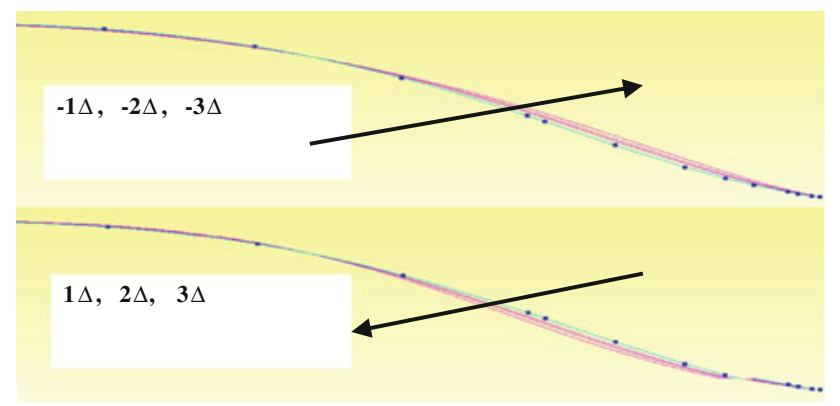

Fig. 6 Design waterline shape as a function of the entrance angle

performance was slightly improved but remained similar to that of the hull form in the second baseline design, with a smaller entrance angle and small bulb. The PMB of the optimal design increase slightly. In the low speed full containership design range, the effect of the LCB position was relatively small within a certain variation range. A reduction in the entrance angle of the SAC resulted in a very narrow waterline angle at the FP. The entrance angle of the optimum SAC was mainly influenced by the incident angle of the design waterline when a bulb shape was given.

Figure 9 shows the wave contours of the optimal design (top) and the baseline design (bottom) at a design speed of 24 knots. Figure 10 shows an experimental setup for a resistance test using the optimal design at the HSVA towing tank. The wave patterns seen in the numerical simulations and model tests were found to be favorable and very stable, respectively. An additional comparison is shown in Fig. 11 that compares the experimental total resistance of the derived ship with that of ships tested at the HSVA. The total resistance of the derived ship was extrapolated from the model test results according to the power prediction methods of the HSVA. The other ships compared in Fig. 11 are from HSVA database; they have similar characteristics for $C_{\mathrm{B}}, \mathrm{L} / \mathrm{B}$ and $\mathrm{B} / \mathrm{T}$ and are scaled to the similar displacement. The derived ship shows excellent resistance performance at the design speed of 24 knots.

During the optimization process, the major part of the improvement was achieved during the first step via systematic parameter variation. This trend depended on the set up of the optimization problem. In this investigation, the first step was to conduct a Pareto search for optimal designs based on a small number of systematic analyses in a wide range of design spaces. Generally, this step is formulated by optimization strategy such as DoE. The selected designs were also used as a starting point for deterministic optimization in the second step. The final optimum design was associated with a relatively small Pareto range.

In the present study, an ultra-large containership hull design was developed using an SAC optimization based on an F-Spline transformation function. This hull form showed good resistance performance although limited longitudinal

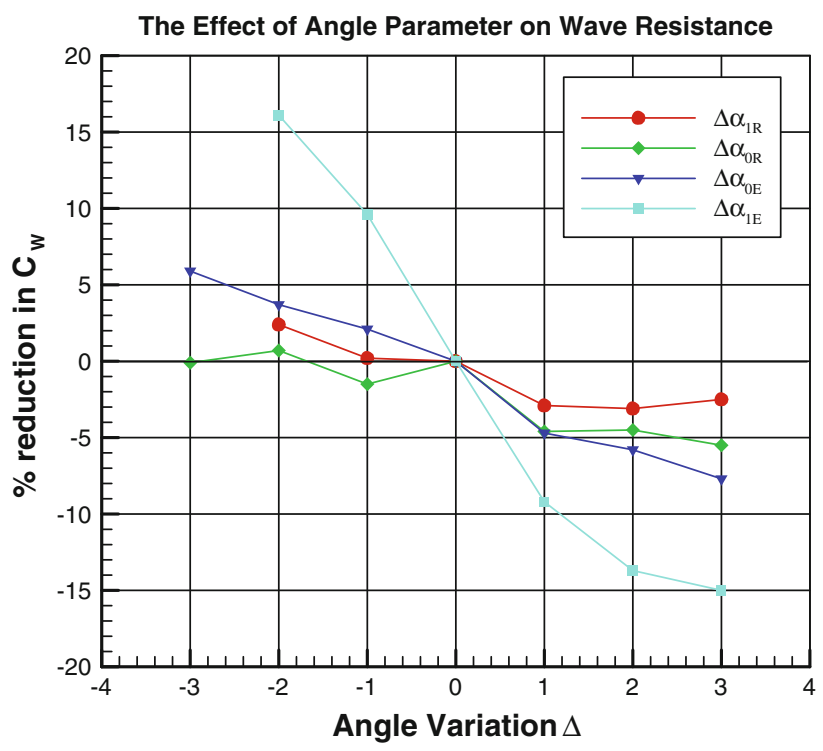

Fig. $7 C_{\mathrm{W}}$ with respect to the tangential angle variation of SAC (entrance and run)

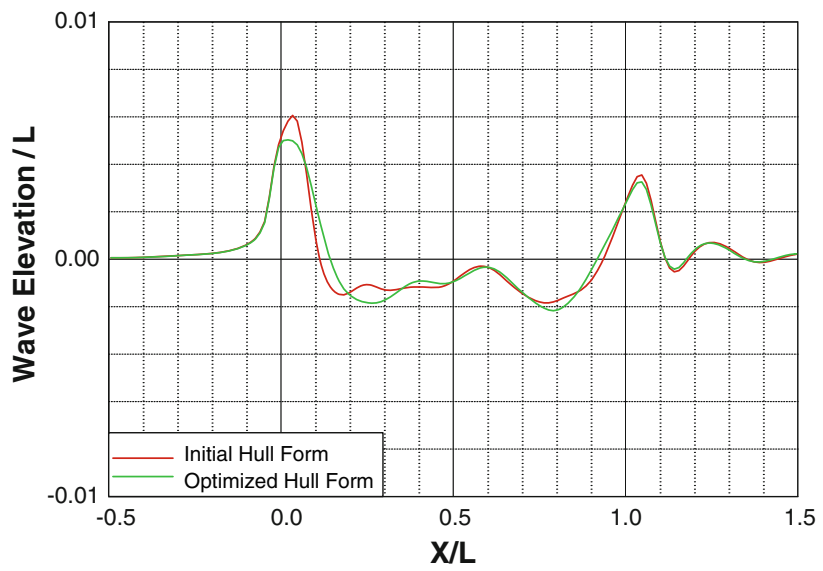

Fig. 8 Comparison of the wave profiles of the baseline design and first design variation

Table 6 Form parameters used for F-Spline variation

\begin{tabular}{ll}
\hline & $\begin{array}{l}\text { F-Spline form } \\
\text { parameter }\end{array}$ \\
\hline Entrance & $\Delta X_{0 \mathrm{E}}, \Delta X_{1 \mathrm{E}}$ (station) \\
& $\Delta \alpha_{0 \mathrm{E}}, \Delta \alpha_{1 \mathrm{E}}\left({ }^{\circ}\right)$ \\
Run & $\Delta X_{0 \mathrm{R}}, \Delta X_{1 \mathrm{R}}$ \\
& $($ station $)$ \\
& $\Delta \alpha_{0 \mathrm{R}}, \Delta \alpha_{1 \mathrm{R}}\left(^{\circ}\right)$ \\
\hline
\end{tabular}

shifting was possible in each section; local variations in the section frame and variations in the bulb shape were not possible. Nevertheless, the simplicity and efficiency of this process are sufficiently valuable to support the use of this technique in the preliminary hull form design stage. 


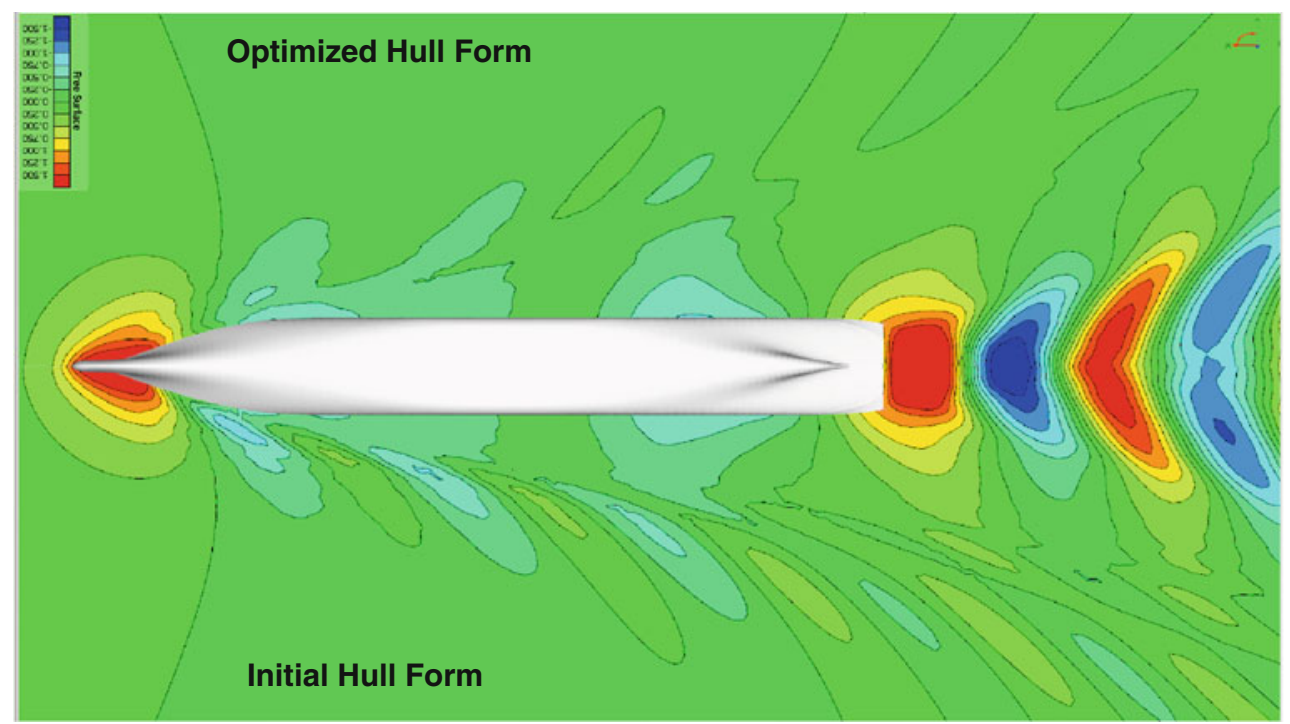

Fig. 9 Wave contour of two hull forms (optimal design baseline design) at 24.0 knots

\section{Full parametric hull form optimization of an LPG carrier}

An LPG carrier is a tanker ship that is designed to transport liquefied petroleum gas. The hydrodynamic hull form design of LPG carriers has generally been considered to involve particular requirements because of the operational peculiarities and geometric limitations of these ships. One such peculiarity is that an LPG carrier operates evenly in the three draft conditions, i.e., the design, ballast, and scantling conditions. Therefore, the speed performance under all draft conditions should be considered at the same time. Similarly, one geometric limitation of the design of these ships is that the LPG tank must be positioned in the most forward part of the ship. This constraint makes it difficult to design a hydrodynamically superior waterline shape and results in increase of wave resistance.

In this section, a hydrodynamic optimization problem is presented for an existing LPG carrier. The baseline design required a performance improvement in the ballast draft condition as the model already showed good hydrodynamic performance in the design draft condition. The aim was to develop a new hull form for an LPG carrier with superior performance in the design and ballast draft conditions. This design problem was complicated not only because it was necessary to set up a constrained multi-objective optimization problem but also because of the volume of shape variations involved in investigating a new geometric concept. The goal of the optimization is to improve the speed performance in the ballast draft condition without decreasing the speed performance in the design draft condition. The forebody hull form was fully parametrically modeled to analyze diverse hull shapes with different

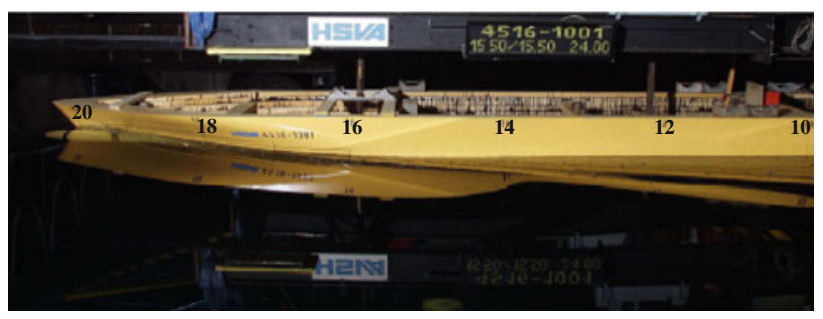

Fig. 10 Model test of the optimized hull form at 24.0 knots

hydrodynamic properties. Table 7 shows the principal characteristics of the target ship.

\subsection{Problem statement for forebody hull form optimization}

The forebody hull form optimization was formulated to minimize the full scale total resistance in the ballast draft condition while maintaining the total resistance in the design condition and satisfying the geometric constraints. The goal of the optimization was to reduce delivery power (DHP) by $3 \%$ in the ballast draft condition while maintaining performance in the design draft condition. The goal was for the new hull form to be compliant with breadth constraints at four frames with nine points for the LPG tank installation. The total displacement change was not to exceed $\pm 3 \%$.

- Minimize

The total resistance, $R_{\mathrm{T}}$, in the ballast draft condition

- Subject to:

Inequality constraint: $R_{\mathrm{T}}$ in the design draft condition Equality constraint: Keeping breadth at four frames Range constraint: Displacement change within $\pm 3 \%$ 
Fig. 11 Comparison of the total resistance of optimized hull form with the HSVA database

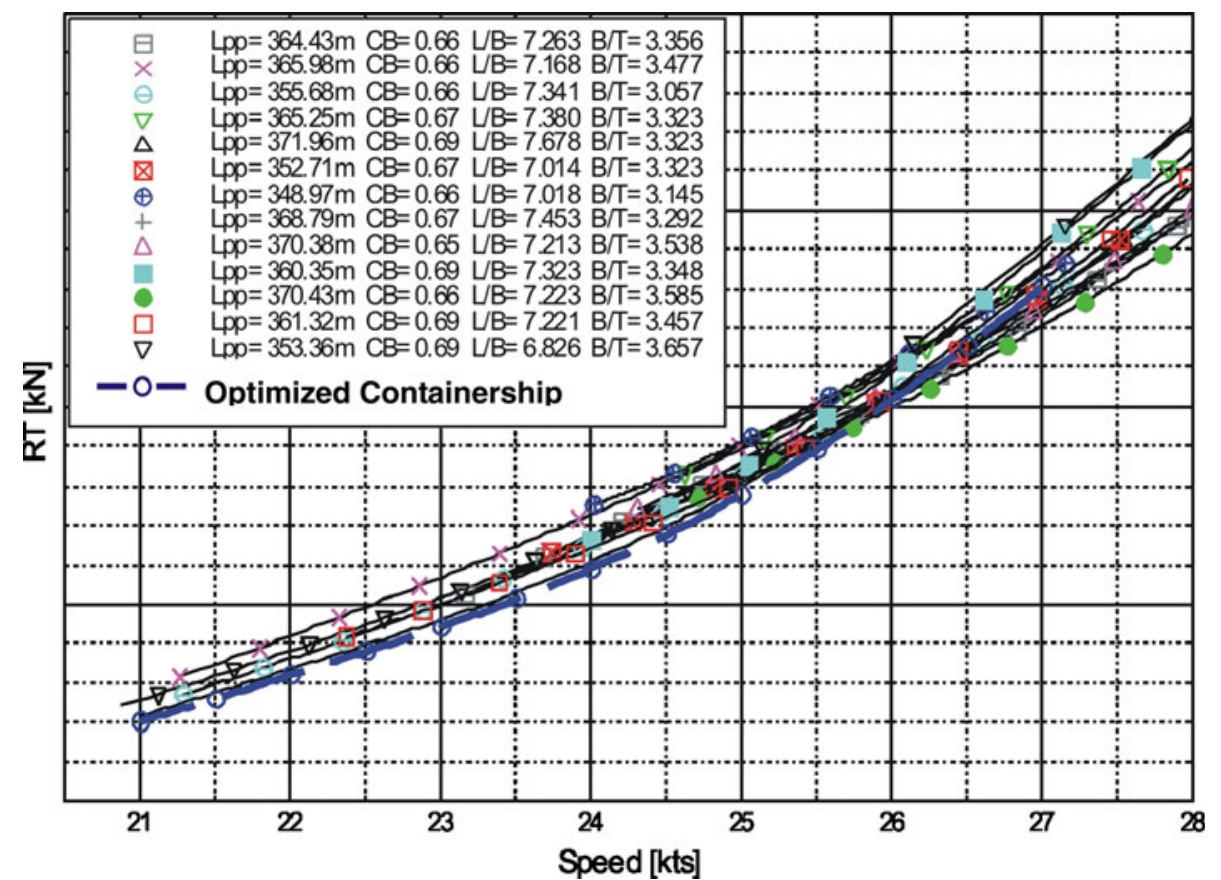

\section{- Objective function}

The total resistance globally reflects the ship performance as a function of the hull form. The total resistance has been utilized as a typical criterion for evaluating hydrodynamic ship performance. In this study, the total resistance at the full scale was compared for the performance evaluation because the scale effect for the model scale ship is not systematic when the performance in two different draft conditions or that of completely different ship shapes is considered. The total resistance at full scale was formulated as

$R_{\mathrm{T}}=R_{\mathrm{WP}}+(1+k) R_{\mathrm{FITTC}}+R_{\mathrm{A}}+\Delta R_{\mathrm{T}}+R_{\mathrm{AA}}$

where $R_{\mathrm{WP}}$ is the wave pattern resistance derived from a wave cut analysis of the wave pattern computed by SHIPFLOW, and $R_{\text {FITTC }}$ is the frictional resistance according to the ITTC friction line,

$C_{\text {FITTC }}=\frac{0.075}{\left(\log _{10} R_{\mathrm{N}}-2\right)^{2}}$

The form factor $k$ of the baseline hull form was estimated using the correlation between that by Holtrop method [11] and measurement tested by MOERI in the design and ballast draft conditions. It yielded $(1+k)=1.229$ for ballast and $(1+k)=1.209$ for design draft of the baseline hull form. During the optimization process, the form factor was recomputed for each design variant based on the empirical form factor [11] that is a function of $L_{\mathrm{PP}}, B, T, L_{\mathrm{R}}, C_{\mathrm{B}}, C_{\mathrm{P}}$ and LCB, which yielded small adjustments. $R_{\mathrm{A}}$ is a correlation allowance,
Table 7 Principal particulars for the LPG carrier

\begin{tabular}{lcl}
\hline & Design condition & Ballast condition \\
\hline$V_{\mathrm{s}}$ (knots) & 16.2 & 16.5 \\
$F_{\mathrm{N}}$ & 0.191 & 0.194 \\
$C_{\mathrm{B}}$ & 0.75 & 0.70 \\
$T(\mathrm{~m})$ & 11.0 & $6.0 / 8.0$ \\
\hline
\end{tabular}

$\Delta R_{\mathrm{T}}$ denotes an additional resistance component, and $R_{\mathrm{AA}}$ represents the wind resistance. The additional resistance components $R_{\mathrm{A}}, \Delta R_{\mathrm{T}}$, and $R_{\mathrm{AA}}$ were estimated at each draft conditions based on the experience with similar ship hulls. These components were applied to each design variant as a function of wetted and exposed surface area respectively.

For the final deterministic optimizations, a mixed objective function was introduced that represented the weighted sum of the total resistance ratios in the ballast and design draft conditions.

The optimization functional was defined as

$$
\begin{array}{r}
F=\frac{2}{3} R_{\text {Tratio }(\mathrm{B})}+\frac{1}{3} R_{\text {Tratio }(\mathrm{D})}+\mathrm{HP}_{\text {Penalty }}+\nabla_{\text {Penalty }} \\
R_{\text {Tratio }}=R_{\mathrm{T}(\text { NewVariant })} / R_{\mathrm{T}(\text { Baseline })}
\end{array}
$$

In Eq. (15), the total resistance ratio $R_{\text {Tratio }}$ is the ratio of the total resistance of the new variant hull to the total resistance of the baseline design. $R_{\text {Tratio(B) }}$ indicates the total resistance ratio in the ballast draft condition and $R_{\text {Tratio(D) }}$ indicates the total resistance ratio in the design draft condition. The total resistance ratios in both conditions were considered in the objective function by 
introducing the corresponding weights. The additional terms $\mathrm{HP}_{\text {Penalty }}$ and $\nabla_{\text {Penalty }}$ are penalty functions which were formulated to account for hard-point and volume constraints. These functions are expressed in Eqs. (16) and (17). The mixed objective function $F$ was introduced to solve the unconstrained deterministic optimization problem by converting the explicit constraints to implicit corresponding exterior penalty functions.

\section{- Constraints}

LPG tank hard-points: There were nine hard-point constraints that were considered for the LPG tanks. In Fig. 12, their locations within the forebody of the baseline design are shown. The hard-point requirements were the leading constraints and, hence, the restricting constraints in the optimization. To address the hard-point constraints in the deterministic optimization, the constraints were formulated as in Eq. (16) and replaced by penalty terms in the objective function. The hard-point penalties $\mathrm{HP}_{i}$ penalty were formulated in terms of normalized exterior penalty functions in a least square sense as

$$
\begin{array}{r}
\mathrm{HP}_{\text {Penalty }}=m_{\mathrm{HP}}\left(H P_{\text {zeroOffset }}+\sum_{i=1}^{9} H P_{i \text { Penalty }}\right) \\
H P_{i \text { Penalty }}=\left\{\begin{array}{cc}
\left(\frac{\delta \mathrm{HP}_{i}}{B \text { Beam } / 2} \times 100\right)^{2} & \text { if } \delta \mathrm{HP}_{i}<0 \\
0 & \text { otherwise }
\end{array}\right\}
\end{array}
$$

$\delta \mathrm{HP}_{i}$ denotes the shortest 1-norm distance from the frame to its respective hard-point $i$, and $m_{\mathrm{HP}}$ is a user defined positive scaling factor. A penalty becomes active only if the respective frame lies inside its hard-point definition. To amplify the penalty in the infeasible domain close to the constraint bound, a constant zero offset $\mathrm{HP}_{\text {zeroOffset }}$ was added to the penalties if and only if one or more hard-point constraints actually became active: i.e., $\delta \mathrm{HP}_{\mathrm{i}}<0$ (for $i=1, \ldots, 9$ ). Finally, all hard-point penalties were added together and added to the mixed objective.

Displacement volume: The change in the displacement volume was required to remain within a margin of $\pm 750 \mathrm{~m}^{3}$. Similar to the hard-point constraints in the final deterministic optimization runs, the displacement constraint was introduced and then fully replaced by a penalty term that was added to the mixed objective function. The penalty was formulated as a rate of increase in the displacement volume as compared with that of the baseline design with an exterior penalty factor as follows:

$$
\nabla_{\text {Penalty }}=\left\{\begin{array}{cc}
m_{\nabla}\left(\frac{\delta \nabla+750 \mathrm{~m}^{3}}{\nabla_{\text {Baseline }}} \times 100\right)^{2} & \text { if } \delta \nabla>750 \mathrm{~m}^{3} \\
0 & \text { otherwise }
\end{array}\right.
$$

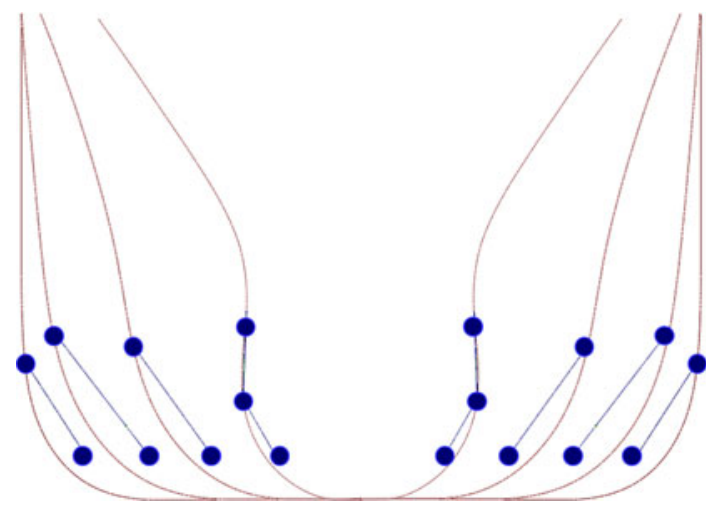

Fig. 12 Hard-point constraints for LPG tank installation

with $\delta \nabla$ representing the change in the displacement volume and $m_{\nabla}$ as a user specified positive scaling factor. As a result, the penalty became active only if the decrease in the displacement volume exceeds the margin of $750 \mathrm{~m}^{3}$. No penalty was used for the upper displacement bound.

\subsection{CFD simulation}

For the performance assessment the potential code XPAN SHIPFLOW [13] was used to compute non-linear ship wave systems with trim and sink. The SHIPFLOW configuration is similar to those described for ultra-large containerships in Sect. 3.2. The hull surface was discretized using 1,940 panels. The free surface domain extended one ship length aft of the stern and to the side and, included 4,025 panels in total. The geometric inputs to SHIPFLOW were based on an offset representation of the ship hull surface. Figure 13 shows grouped (differently colored) SHIPFLOW offsets for the baseline LPGC hull.

\subsection{Optimization procedure}

Two step optimizations were performed. In the first step, a systematic design space exploration was conducted based on the Sobol algorithm using the design of experiments (DoE) procedure $[7,25]$. The primary purpose of analyzing the design space was to detect reasonable starting points for deterministic optimization. Throughout the optimization process, both the ballast and the design draft were monitored for the targeted speeds, respectively. Through the design space analysis, 2,470 designs were generated in total. The 946 feasible designs that fulfilled the necessary constraints are shown in Fig. 14. This figure shows the designs that were successfully analyzed by the Sobol algorithm in the generalized design space, which, for $N$ free variables, maps the multidimensional design space from $R^{N}$ 
into the domain of the generalized design variables $X$ and $Y$ : i.e., $R^{2}$ with

$X_{\text {norm }}=\sqrt{\sum_{i=1}^{N / 2} f_{i}^{2}}, \quad Y_{\text {norm }}=\sqrt{\sum_{i=N / 2+1}^{N} f_{i}^{2}}$

$f_{i}$ denotes the value of the free variable $i$ mapped into the normalized domain of its lower and upper bound [0..1] [8].

The feasible designs were further analyzed by means of CFD. Based on the design space exploration, deterministic optimizations from different start designs were performed. Figure 15 shows the range of improvement in the total resistance in two draft conditions at the same time. The designs in the bounded square are Pareto optimal with minimum total resistance in both the ballast and design draft conditions. These studies indicate that the bulb shape and the incident angle of the waterlines influence the wave resistance performance in the ballast draft condition. The hull form variations are focused on this area and the second stage of deterministic optimization was restarted. Figure 16 shows part of convergence history for the objective functions in the ballast draft condition.

\subsection{Optimum hull form and performance}

The final optimum hull form is shown in Fig. 17. The forebody profile and bulb shape are remarkably different from those of the conventional LPG ship. They are similar to those of a low speed container ship. The volume distribution around the ballast draft and bottom area was considerably reduced, whereas the volume near the design draft increased. All geometrical constraints were satisfied.

The wave contour in the ballast draft condition is shown in Fig. 18 for the optimal ship. A decrease of $1.75 \%$ in the total resistance in the ballast draft condition and a decrease of $0.98 \%$ in the design draft condition were achieved using SHIPFLOW simulation. The wetted surface area $S$ was substantially reduced in both conditions. The selected design features a smaller bulbous bow and a finer entrance angle that is expected to decrease the wave breaking in the ballast draft condition at around 16.5 knots. The resistance and propulsion tests were performed in the towing tank at MOERI, Korea. The performance of the two hull forms is compared for two draft conditions in Table 8. In the ballast draft condition, the optimum hull form shows a $5.7 \%$ improvement in the total resistance $R_{\mathrm{TS}}$ and a $7.8 \%$ improvement in delivery power.
A comparison the total resistance achieved via the CFD simulation with that indicated in the EFD results yields some discrepancies. The improvement in the resistance performance of the optimal ship is much greater in the EFD case than in the CFD case. This still holds given the experimental and computational uncertainties involved. The new bulb may result in favorable wave-viscous interaction not only by reducing the breaking waves but also by influencing the stern wave and boundary. The scale effect extrapolated from model to ship, in which the form factor must be used, should be carefully considered. In any case,

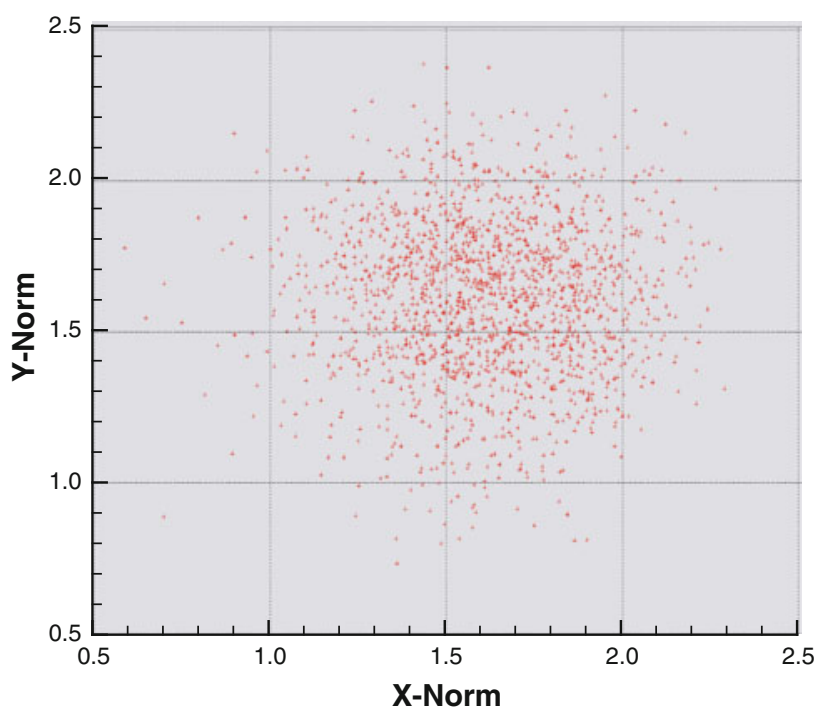

Fig. 14 Generalized design space $X$ over $Y$

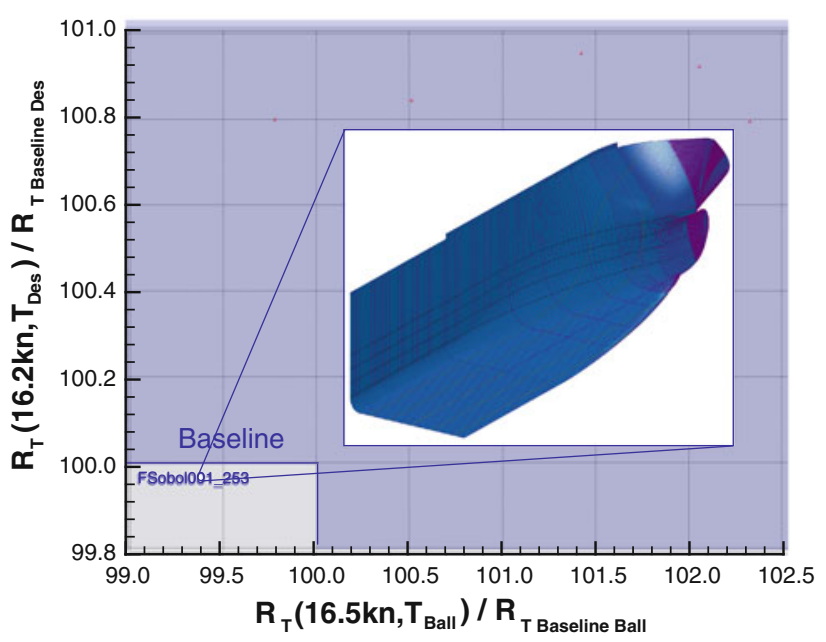

Fig. 15 Definition of the feasible designs

Fig. 13 SHIPFLOW offset of the LPGC baseline hull

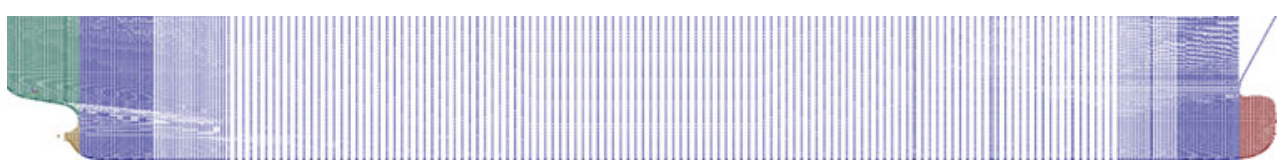


this type of forebody hull form is favorable for propulsion and resistance performance.

\section{Conclusions}

This study involved hydrodynamic hull form optimizations based on parametric models generated by F-Spline. Two functionalities of F-Spline in the context of ship design were validated through this research. They were used to evaluate shape distortion as constrained transformation

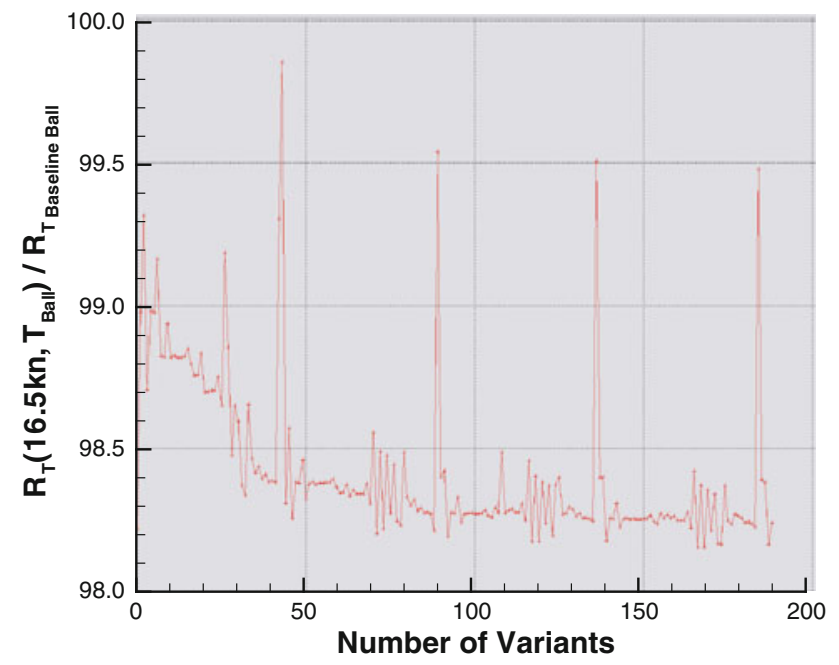

Fig. 16 Convergence history plot of the objective function in the ballast condition functions and for form parameter design as fully parametric models. This design process can be considered as a relevant design method in the preliminary design stage for the following reasons:

1. Since F-Spline is automatically generated via the optimization process for fairness to satisfy the given requirements, a fair curve is always generated even with a few subsets of form parameters available to satisfy the given requirements. This curve can, therefore, be easily used in the complicated form generation and form transformation processes.

2. Hull form distortion based on the constrained transformation function F-Spline is simple, flexible, and well suited to the optimization process. In particular, the implementation of differential form parameters for the SAC transformation remarkably improved the availability of the hull form distortion by transforming the entrance angle and stern profile shape, which are significant factors in resistance performance. An ultralarge container ship optimized using this process showed excellent resistance performance at the design speed of 24 knots.

3. The fully parametric ship hull design offers the flexibility to generate new types of hull forms. This holds even if it is still difficult to model and control the ship hull because of its complex structure. This design approach was used in forebody hull form optimization for an LPG carrier. The optimal ship with a completely different bulb shape was successfully validated,
Fig. 17 Comparison of the optimum forebody hull form (blue, small bulb) and initial hull form (red, large bulb) (color figure online)
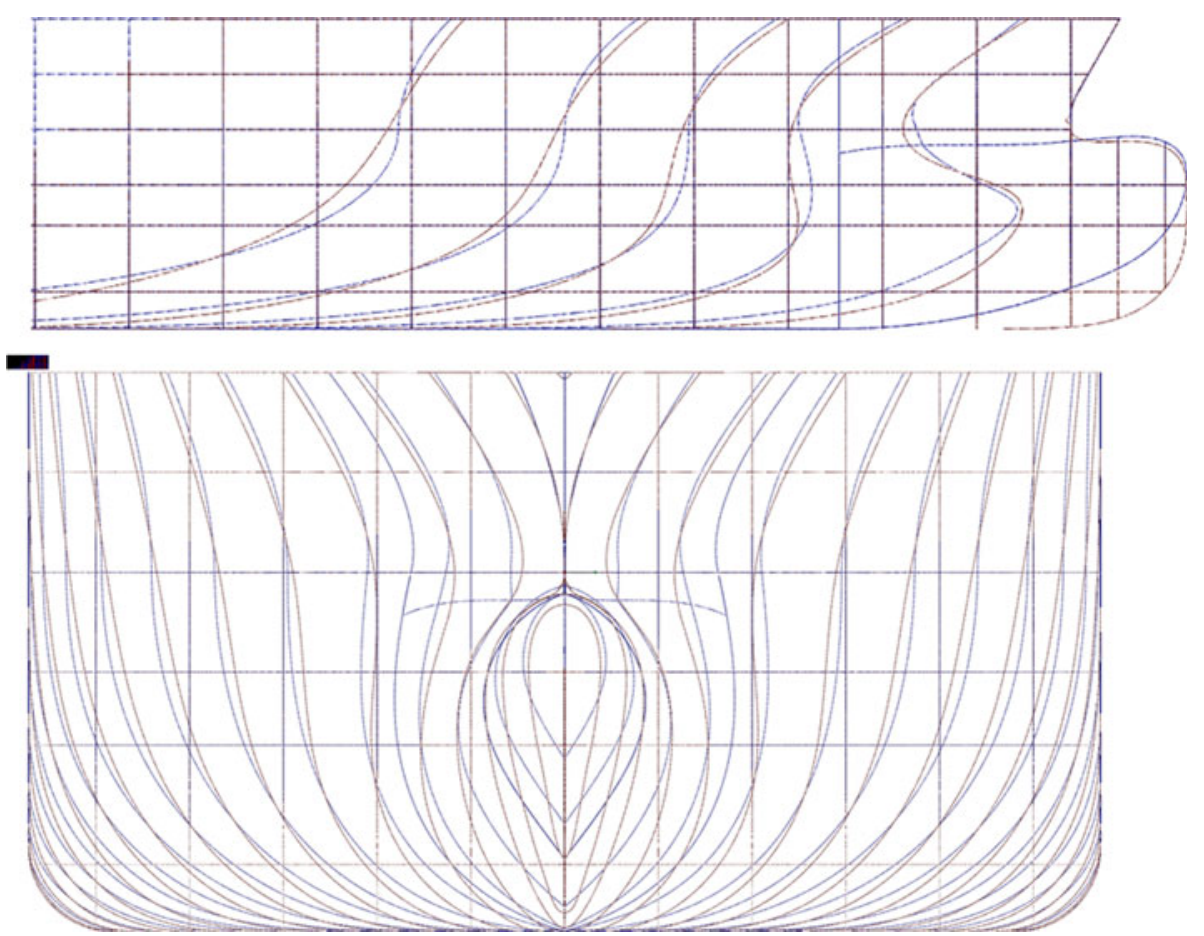


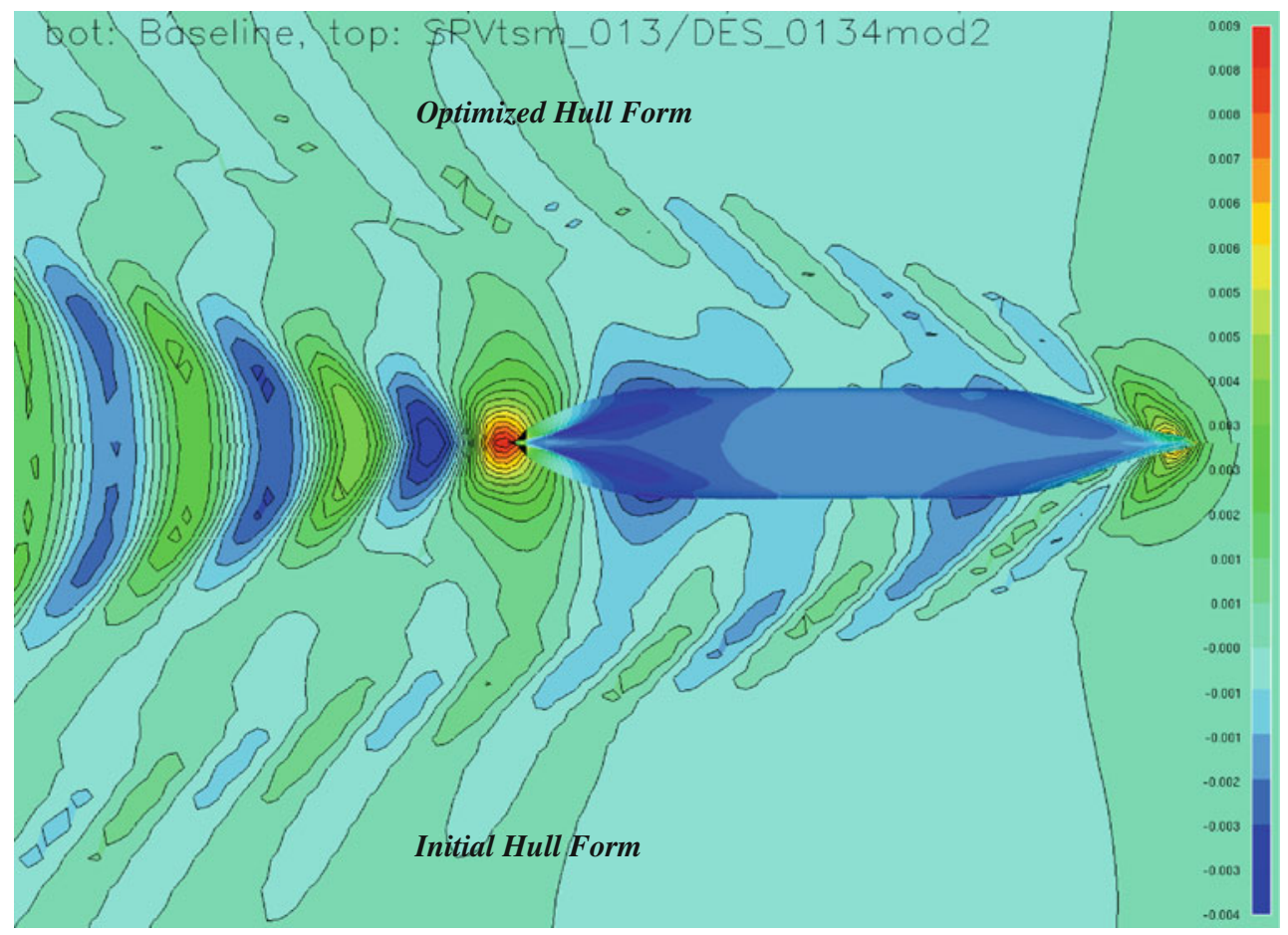

Fig. 18 Comparison of wave contours

Table 8 Improvements in performance characteristics

\begin{tabular}{lll}
\hline & Design condition $(\%$ diff.) & Ballast condition $(\%$ diff.) \\
\hline$S$ & -1.06 & -1.20 \\
$\nabla$ & -0.36 & -0.99 \\
$R_{\mathrm{TS}}$ & $0.74 /-0.98(\mathrm{CFD})$ & $-5.70 /-1.75(\mathrm{CFD})$ \\
$R_{\mathrm{TM}}$ & -0.99 & -4.22 \\
$P_{\mathrm{D}}$ & -0.50 & -7.79 \\
$C_{\mathrm{R}}$ & 5.38 & -10.08 \\
$C_{\mathrm{TS}}$ & 1.81 & -4.54 \\
\hline
\end{tabular}

$\%$ diff. $=($ optimized-initial $) /$ initial $\times 100$

showing a $5.7 \%$ improvement in total resistance and a $7.8 \%$ improvement in delivery power.

4. The flexibility and functionality of geometric modeling constitutes an important technology in hydrodynamic optimization, not only because it is directly related to the performance of the optimal hull form but also because it is related to the effectiveness and automation of the optimization process.

Acknowledgments This research was supported by World Class University (WCU) program through the National Research Foundation of Korea funded by the Ministry of Education, Science and Technology (R31-2008-000-10045-0). The author would like to thank Prof. K.C. Park of University of Colorado at Boulder for his sincere advice and encouragement and Dr. Stefan Harries of Friendship Systems GmbH for his long and constant friendship.
Open Access This article is distributed under the terms of the Creative Commons Attribution Noncommercial License which permits any noncommercial use, distribution, and reproduction in any medium, provided the original author(s) and source are credited.

\section{References}

1. Abt C, Harries S (2007) A new approach to integration of CAD and CFD for naval architects. In: Sixth international conference on computer applications and information technology in the maritime industries (COMPIT), Cortona

2. Birk L, Harries S (eds) (2003) OPTIMISTIC—optimization in marine design, Mensch \& Buch Verlag, Berlin, ISBN 3-89820514-2

3. Campana EF, Liuzzi G, Lucidi S, Peri D, Piccialli V, Pinto A (2009) New global optimization methods for ship design problems. Optim Eng 10:533-555

4. Campana EF, Peri D, Tahara Y et al (2006) Shape optimization in ship hydrodynamics using computational fluid dynamics. Comput Methods Appl Mech Eng 196:634-651

5. Campana EF, Peri D, Tahara Y (2004) Comparison and validation of CFD based local optimization methods for surface combatant bow. In: 25th symposium on naval hydrodynamics, St. John's, Newfoundland and Labrador, Canada, August 8-13

6. Harries S (1998) Parametric design and hydrodynamic optimization of ship hull forms. Ph.D. Thesis, Institut für Schiffs-und Meerestechnik, Technische Universität Berlin, Germany; Mensch \& Buch Verlag, Berlin

7. Harries S, Valdenazzi F, Abt C, Viviani U (2001) Investigation on optimization strategies for the hydrodynamic design of fast ferries, FAST'01, Southampton 
8. Harries S, Abt C, Hochkirch K (2004) Constraint management for marine design applications. In: International symposium on practical design of ships and other floating structures (PRADS 2004), Lübeck-Travemünde, Germany, September 2004

9. Harries S, Friendship Systems (2007) Hydrodynamic optimization of the DSME 60K LPG Carrier, FS-Report 175-02-01

10. Hinatsu M (2004) Fourier NUBS method to express ship hull form. J Mar Sci Technol 9:43-49

11. Holtrop J (1984) A statistical re-analysis of resistance and propulsion data. Int Shipbuild Progress 31(363):272-276

12. Lackenby $H$ (1950) On the systematic geometrical variation of ship forms. Trans INA 92:289-316

13. Larsson L (1997) SHIPFLOW user's manual and theoretical manual, FLOWTECH Int. AB, Gothenburg

14. Lee YS, Kim SY, Kang KT (1995) Hull form generation by using TSK fuzzy model. Fuzzy logic and its application, information science and intelligence systems

15. Lee YS (2003) Trends validation of CFD predictions for ship design purpose. Ph.D. Thesis, Institut für Schiffs-und Meerestechnik, Technische Universität Berlin, Germany

16. Maisonneuve JJ, Harries S, Marzi J, Raven HC, Viviani U, Piippo H (2003) Toward optimal design of ship hull shapes. In: 8th international marine design conference, IMDC03, Athens

17. Min KS, Lee YS, Han BW, Kang SH (2004) Hull form optimization for fine higher-speed ships. In: 25th symposium on naval hydrodynamics, St. John's, Newfoundland and Labrador, Canada, August 8-13

18. Nowacki H, Creutz G, Munchmeyer FC (1977) Ship lines creation by computer-objectives, methods, and results, symposium on computer-aided hull surface definition. Annapolis, MD

19. Nowacki H, Boor MIG, Oleksiewicz B (1995) Computational geometry for ships. World Scientific, Singapore

20. Nowacki H, Kaklis PD (eds) (1998) Creating FAIR and SHAPEpreserving curves and surfaces. B.G. Teubner, Stuttgart

21. Papanikolaou A, Zaraphonitis G, Boulougouris E, Langbecker U, Matho S, Sames P (2010) Multi-objective optimization of oil tanker design. J Mar Sci Technol 15:359-373

22. Pérez-Arribas F, Suárez-Suárez JA, Fernández-Jambrina L (2006) Automatic surface modeling of a ship hull. Comput Aided Des 38:584-594
23. Pérez F, Suárez JA, Clemente JA, Souto A (2007) Geometric modeling of bulbous bows with the use of non-uniform rational B-Spline surfaces. J Mar Sci Technol 12:83-94

24. Peri D, Campana EF (2005) High-fidelity models and multi objective global optimization algorithms in simulation-based design. J Ship Res 49:159-175

25. Press WH, Flannery BP, Teukolsky SA, Vetterling WT (1988) Numerical recipes in C. Cambridge University Press, New York

26. Saha GK, Suzuki K, Kai H (2004) Hydrodynamic optimization of ship hull forms in shallow water. J Mar Sci Technol 9:51-62

27. Saha GK, Suzuki K, Kai H (2005) Hydrodynamic optimization of a catamaran hull with large bow and stern bulbs installed on the center plane of the catamaran. J Mar Sci Technol 10:32-40

28. Sariöz E (2006) An optimization approach for fairing of ship hull forms. Ocean Eng 33:2105-2118

29. Stern F, Wilson RV, Coleman HW (2001) Comprehensive approach to verification and validation of CFD simulations-part 1: methodology and procedures. J Fluid Eng 123:793-802

30. Tahara Y, Stern F, Himeno Y (2004) CFD-based optimization of a surface combatant. J Ship Res 28:159-175

31. Tahara Y, Wilson RV, Carrica PM, Stern F (2006) RANS simulation of a container ship using a single-phase level-set method with overset grids and the prognosis for extension to a self-propulsion simulator. J Mar Sci Technol 11:209-228

32. Tahara Y, Peri D, Campana EF, Stern F (2008) Computational fluid dynamics-based multiobjective optimization of a surface combatant using a global optimization method. J Mar Sci Technol 13:95-116

33. Valdenazzi F, Harries S, Viviani U, Abt C (2002) Seakeeping optimisation of fast vessels by means of parametric modeling, HSMV02, Naples

34. Valorani M, Peri D, Campana EF (2003) Sensitivity analysis methods to design optimal ship hulls. Optim Eng 4, 337-364

35. Wilson RV, Stern F, Coleman HW (2001) Comprehensive approach to verification and validation of CFD simulations-part 2: RANS simulation of a cargo/container ship. J Fluid Eng 123:803-810 